\title{
Association between hypertension and coffee drinking based on CYP1A2 rs762551 single nucleotide polymorphism in Taiwanese
}

\author{
Chien-Chou Hou ${ }^{1,2}$, Disline Manli Tantoh ${ }^{3,4}$, Chuan-Chao Lin ${ }^{5,6}$, Pei-Hsin Chen ${ }^{4}$, Hao-Jan Yang ${ }^{4,7^{*}}$ and \\ Yung-Po Liaw $3,4^{*}$ (D)
}

\begin{abstract}
Background: Hypertension increases the likelihood of cardiovascular diseases (CVDs). Cytochrome P450 1A2 (CYP1A2) single nucleotide polymorphism (SNP) is related to caffeine metabolism and the risk of CVD among coffee drinkers. CYP1A2 rs762551 influenced the risk of stroke among hypertensive patients. We examined the relationship between hypertension and coffee drinking based on CYP1A2 rs762551 SNP in Taiwanese adults.

Methods: We used data contained in the Taiwan Biobank database (2011-2018) and included 19,133 participants having complete information on hypertension, rs 762551 polymorphism, coffee intake, etc. The risk of hypertension was determined using multiple logistic regression.

Results: Coffee intake was significantly associated with a lower risk of hypertension. The odds ratio (OR), 95\% confidence interval (CI), and p-value were $0.877,0.807-0.954$, and 0.0032, respectively. CYP1A2 rs762551 was not significantly associated with the risk of hypertension, but it had a significant interactive association with coffee drinking ( $p$ value $=0.0303$ ). After stratification by rs762551 genotypes, the inverse coffee drinking-hypertension association was retained, but significant results were observed only in those with the AC + CC genotype (OR 0.678, 95\% CI 0.722-900, $p$ value $=0.0001$ ). According to the combination of coffee drinking and rs762551 genotypes (reference group: no coffee drinking and rs762551 AA), the coffee drinking-AC + CC group had a lower risk of hypertension (OR 0.888, 95\% $\mathrm{Cl} 0.789-0.999, p$ value $=0.0483$ )
\end{abstract}

Conclusion: Coffee drinking, particularly among individuals with the CYP1A2 rs762551 AC + CC genotype was associated with lower odds of hypertension.

Keywords: Hypertension, Coffee drinking, CYP1A2, rs762551, Taiwanese

*Correspondence: hjyang@csmu.edu.tw; Liawyp@csmu.edu.tw

${ }^{4}$ Department of Public Health and Institute of Public Health, Chung Shan

Medical University, No. 110 Sec. 1 Jianguo N. Road, Taichung City 40201, Taiwan

Full list of author information is available at the end of the article

\section{Background}

Hypertension is a significant public health burden. Its prevalence among adults has been increasing. In 2000, about 972 million adults in the world were believed to be hypertensive [1]. However, by 2010, hypertension among adults was estimated at 1.4 billion [2]. It is projected at about 1.56 billion by 2025 [1]. The disease is multiplying rapidly in Asia, and the prevalence rate in Taiwan is about $25 \%$ in men and $18 \%$ in women [3]. Hypertension increases the likelihood of CVDs like heart failure, stroke, original author(s) and the source, provide a link to the Creative Commons licence, and indicate if changes were made. The images or other third party material in this article are included in the article's Creative Commons licence, unless indicated otherwise in a credit line to the material. If material is not included in the article's Creative Commons licence and your intended use is not permitted by statutory regulation or exceeds the permitted use, you will need to obtain permission directly from the copyright holder. To view a copy of this licence, visit http://creativecommons.org/licenses/by/4.0/. The Creative Commons Public Domain Dedication waiver (http://creativeco mmons.org/publicdomain/zero/1.0/) applies to the data made available in this article, unless otherwise stated in a credit line to the data. 
and coronary heart disease $[1,4-6]$, which account for a considerable number of global deaths $[7,8]$. The burden of deaths attributable to CVDs was approximately 12.3 and 17.3 million in 1990 and 2013, respectively [7], and 17.92 million in 2015 [8]. Some cardiovascular outcomes are believed to be the consequence of the effect of coffee on blood pressure (BP) [9].

Coffee consumption has been increasing in Taiwan and the world $[10,11]$. Dietary and lifestyle factors play substantial roles in modifying the risk of hypertension [12]. A previous study indicated that regular consumption of three or more cups of coffee a day was protective against hypertension [13]. In the SUN project, regular consumption of coffee was associated with a decreased risk of hypertension (about 26\%) only in women [14]. A meta-analysis suggested that long-term consumption of coffee may lower the incidence of hypertension [15]. Daily intake of green or black tea was associated with a modest increase in hypertension risk [16]. However, the risk became non-significant when caffeine was adjusted for in the model. Marjan and colleagues found that regular intake of tea reduced systolic blood pressure (SBP) and diastolic blood pressure (DBP) by $4.81 \mathrm{mmHg}$ and $1.98 \mathrm{mmHg}$, respectively [17].

So far, findings from epidemiological research on coffee drinking and hypertension have been controversial [4]. Some short-term intervention studies revealed a positive association [18]. However, one prospective study found that coffee intake was beneficial for hypertension only among non-smokers [19] while several prospective studies found that coffee intake could elevate the risk of hypertension [20-23].

Genetic factors contribute to variability in the effect of coffee on cardiovascular health [24]. Specific genetic polymorphisms related to caffeine metabolism pose a risk of CVD among coffee drinkers. For instance, polymorphism at CYP1A2 rs762551 was associated with impaired caffeine metabolism, owing to low enzyme actions [25]. This variant was also associated with stroke risk in a Chinese population with hypertension, cerebral infarction, and coronary heart disease [26]. About $95 \%$ of caffeine metabolism is attributed to CYP1A2 [27]. CYP1A2 modulated the effect of caffeinated coffee on myocardial infarction [28] and its polymorphism was associated with hypertension [29]. Moreover, caffeine intake modified the association between CYP1A2 variants and blood pressure (BP) among European adults [30, 31]. Research on hypertension based on CYP1A2 polymorphism and coffee intake in Taiwanese is seemingly rare. Considering the controversial influence of coffee on hypertension and cardiovascular health, and the importance of genetic insights in the management of diseases in this era, we undertook this study to evaluate the relationship between hypertension and coffee drinking based on CYP1A2 rs762551 single nucleotide polymorphism in Taiwanese.

\section{Methods \\ Data source}

We conducted this study using data contained in the Taiwan Biobank database (2011-2018). The biobank contains genetic data as well as information like medical history, sex, age, diet, and other lifestyle factors. Enrolment into the Taiwan Biobank project is restricted to Taiwanese adults between 30 and 70 years without a personal history of cancer.

\section{Study population and variable definitions}

Variables included hypertension (yes/no), coffee drinking (yes/no), rs762551 genotypes (AA/AC $+\mathrm{CC}$ ), tea drinking (yes/no), sex (men/women), age, body mass index or simply BMI (underweight/normal /overweight/ obese), cigarette smoking (never/former/current), alcohol drinking (never/former/current), and exercise (no/ yes). Hypertensive cases were those who confirmed through questionnaires to have ever been clinically diagnosed with the disease. Coffee drinking was defined according to self-reports on weekly consumption frequency. The coffee-drinking group included individuals who self-reported a habit of drinking coffee at least thrice per week while the non-drinking group included those who habitually drank coffee less than three times per week. Tea drinking was defined based on daily consumption frequency. The tea-drinking category included those who self-reported a habitual daily tea intake of at least one time while the non-drinking category included those who had a habit of not drinking tea every day. Sex and age were self-reported while BMI was derived from weight $(\mathrm{kg})$ and height $(\mathrm{m})$ using the standard formula: weight divided by (height) ${ }^{2}$. Underweight was defined as $\mathrm{BMI}<18.5 \mathrm{~kg} / \mathrm{m}^{2}$, normal $\mathrm{BMI}$ as $18.5 \leq \mathrm{BMI}<24 \mathrm{~kg} /$ $\mathrm{m}^{2}$, overweight as $24 \leq \mathrm{BMI}<27 \mathrm{~kg} / \mathrm{m}^{2}$, and obesity as $\mathrm{BMI} \geq 27 \mathrm{~kg} / \mathrm{m}^{2}$. Participants were considered nonsmokers if they had no history of cigarette smoking for continuously 6 months or more. Former smokers were those who smoked cigarettes continuously for at least 6 months but were not smoking during data collection. Current smokers were those who had a history of continuous cigarette smoking for at least 6 months and were still smoking during data collection. Participants were considered non-drinkers if they had no history of continuous drinking for 6 months or drank less than $150 \mathrm{cc}$ of alcohol per week. Former drinkers were those who abstained from alcohol for more than 6 months while current drinkers were those who drank at least $150 \mathrm{cc}$ of alcohol per week continuously for 6 months. Exercise was defined as regular exercise taken 3 times a 
week (with each session lasting over $30 \mathrm{~min}$ ). This study included 3411 hypertensive and 15,722 non-hypertensive individuals. All participants signed an informed consent letter. We obtained ethical approval from the Institutional Review Board of Chung Shan Medical University (CS1-20,009).

\section{Statistical analyses}

CYP1A2 rs762551 was validated using quality control measures including, Hardy-Weinberg equilibrium $p>0.001$, a minor allele frequency $\geq 0.05$, and call rate $\geq 0.05$. Quality control was performed using PLINK version 1.9. Chi-square test was used to differentiate the categorical variables while Student's $T$ test was used to differentiate the continuous variables between cases and non-cases. Categorical variables were presented as $n$ (percentage) and continuous variables as mean \pm standard error. Multivariate logistic regression was used to evaluate the association of coffee drinking and rs762551 with hypertension and also the interaction between coffee drinking and rs762551. Statistical analyses were performed using SAS version 9.4 (SAS Institute Inc., Cary, North Carolina, USA), and $p$ values less than 0.05 were considered to be statistically significant.

\section{Results}

Table 1 shows the demographic data of 19,133 participants stratified as coffee drinkers $(\mathrm{n}=7766)$ and nondrinkers $(n=11,367)$. Of the 19,133 participants, 3411 were hypertensive while 15,722 were non-hypertensive. Coffee drinkers and non-drinkers significantly differed according to hypertension $(p$ value $<0.0001)$ but not according to rs762551 genotypes ( $p$ value $=0.8659$ ). Coffee drinkers and non-drinkers also differed in terms of tea drinking ( $p$ value $<0.0001)$, sex $(p$ value $=0.0154)$, age, BMI, cigarette smoking, and alcohol drinking ( $p$ value $<0.0001$ ) but not exercise ( $p$ value $=0.2581$ ).

Table 2 shows the association of hypertension with coffee and other variables. Coffee intake was significantly associated with a lower (OR 0.877, 95\% CI 0.807-0.954, $p$ value $=0.0032)$ while the rs762551 variant was associated with a higher but not significant risk of hypertension (OR 1.021, 95\% CI 0.941-1.107, $p$ value $=0.6176$ ).

The rs762551 variant had a significant interaction with coffee $(p$ value $=0.0303)$ but not with tea $(p$ value $=0.4183$ ) as seen in Table 3 . After stratification by rs762551 genotypes, coffee drinking was significantly associated with a lower risk of hypertension only in those with the AC+CC genotype (OR0.806, 95\% CI0.722$0.900, p$ value $=0.0001$ ). Further stratification of coffee drinking revealed a significant dose-response association ( $p$ value $<0.0001)$ between coffee drinking and hypertension in those carrying the AC $+\mathrm{CC}$ genotype (Table 4).
Table 1 Demographic data of participants according to coffee drinking habits

\begin{tabular}{|c|c|c|c|}
\hline Variables & $\begin{array}{l}\text { No coffee drinking } \\
(n=11,367)\end{array}$ & $\begin{array}{l}\text { Coffee drinking } \\
(n=7766)\end{array}$ & $p$ value \\
\hline Hypertension & & & $<0.0001$ \\
\hline No & $9215(81.07)$ & 6507(83.79) & \\
\hline Yes & 2152(18.93) & $1259(16.21)$ & \\
\hline rs762551 genotype & & & 0.8659 \\
\hline$A A$ & $4844(42.61)$ & $3319(42.74)$ & \\
\hline$A C+C C$ & 6523(57.39) & $4447(57.26)$ & \\
\hline Tea drinking & & & $<0.0001$ \\
\hline No & 8859(77.94) & $5610(72.24)$ & \\
\hline Yes & $2508(22.06)$ & $2156(27.76)$ & \\
\hline Sex & & & 0.0154 \\
\hline Women & $7277(64.02)$ & $5104(65.72)$ & \\
\hline Men & 4090(35.98) & 2662(34.28) & \\
\hline Age (years) & $55.70 \pm 0.0951$ & $54.08 \pm 0.1125$ & $<0.0001$ \\
\hline$B M I$ & & & $<0.0001$ \\
\hline Underweight & $364(3.20)$ & 169(2.18) & \\
\hline Normal & $5544(48.77)$ & $3653(47.04)$ & \\
\hline Overweight & $3286(28.91)$ & 2332(30.03) & \\
\hline Obesity & 2173(19.12) & 1612(20.76) & \\
\hline Cigarette smoking & & & $<0.0001$ \\
\hline Never & $9385(82.56)$ & $6145(79.13)$ & \\
\hline Former & $1212(10.66)$ & $997(12.84)$ & \\
\hline Current & $770(6.77)$ & $624(8.04)$ & \\
\hline Alcohol drinking & & & $<0.0001$ \\
\hline Never & $10,234(90.03)$ & 6825(87.88) & \\
\hline Former & $461(4.06)$ & 309(3.98) & \\
\hline Current & $672(5.91)$ & $632(8.14)$ & \\
\hline Exercise & & & 0.2581 \\
\hline No & $5766(50.73)$ & $4004(51.56)$ & \\
\hline Yes & $5601(49.27)$ & $3762(48.44)$ & \\
\hline
\end{tabular}

According to the combination of coffee drinking and the rs762551 genotypes (Table 5) with the reference group being no coffee drinking and the rs762551 AA genotype, the risk of hypertension was lower in the coffee drinking and AC + CC group (OR 0.888, CI 0.789-0.999, $p$ value $=0.0483$.

\section{Discussion}

We used the 2011-2018 Taiwan Biobank cohort in the current study. Descriptive data showed that coffee drinkers and non-drinkers significantly differed according to hypertension but not according to the rs762551 genotypes. Logistic regression analysis also revealed a non-significant association between $\mathrm{AC}+\mathrm{CC}$ genotype (reference: AA) and coffee drinking (data not shown). After multivariate logistic regression analysis, coffee 
Table 2 Multiple logistic regression model showing the association between coffee drinking and hypertension

\begin{tabular}{|c|c|c|c|}
\hline Variables & OR & $95 \% \mathrm{Cl}$ & p-value \\
\hline \multicolumn{4}{|c|}{ Coffee drinking (Reference: No) } \\
\hline Yes & 0.877 & $0.807-0.954$ & 0.0032 \\
\hline \multicolumn{4}{|c|}{ rs762551 genotype (Reference: AA) } \\
\hline$A C+C C$ & 1.021 & $0.941-1.107$ & 0.6176 \\
\hline \multicolumn{4}{|c|}{ Tea drinking (Reference: No) } \\
\hline Yes & 0.988 & $0.899-1.086$ & 0.8002 \\
\hline \multicolumn{4}{|c|}{ Sex (Reference: Women) } \\
\hline Men & 1.241 & $1.123-1.371$ & $<0.0001$ \\
\hline Age & 1.094 & $1.088-1.099$ & $<0.0001$ \\
\hline \multicolumn{4}{|c|}{ BMI (Reference: Normal) } \\
\hline Underweight & 0.222 & $0.129-0.382$ & $<0.0001$ \\
\hline Overweight & 2.018 & $1.831-2.224$ & $<0.0001$ \\
\hline Obesity & 4.421 & $3.989-4.901$ & $<0.0001$ \\
\hline \multicolumn{4}{|c|}{ Cigarette smoking (Reference: Never) } \\
\hline Former & 1.159 & $1.016-1.323$ & 0.0283 \\
\hline Current & 1.010 & $0.849-1.201$ & 0.9119 \\
\hline \multicolumn{4}{|c|}{ Alcohol drinking (Reference: Never) } \\
\hline Former & 1.502 & $1.253-1.800$ & $<0.0001$ \\
\hline Current & 1.366 & $1.166-1.601$ & 0.0001 \\
\hline \multicolumn{4}{|c|}{ Exercise(Reference: No) } \\
\hline Yes & 1.032 & $0.947-1.123$ & 0.4737 \\
\hline
\end{tabular}

OR: odds ratio, $\mathrm{Cl}$ : confidence interval drinking had a significant inverse association with hypertension. CYP1A2 rs762551 was not significantly associated with the risk of hypertension but had a significant interaction with coffee drinking. After stratifying participants by rs762551 genotypes, the inverse coffee-hypertension association was retained only among those with the $\mathrm{AC}+\mathrm{CC}$ genotype. Combining coffee and rs762551 genotypes revealed a lower risk of hypertension among coffee drinkers with the $\mathrm{AC}+\mathrm{CC}$ genotype. The inverse association between coffee drinking and hypertension in the $\mathrm{AC}+\mathrm{CC}$ group was in a dose-dependent manner.

The non-significant association between coffee drinking and rs762551 genotype observed in the current study is in concordance with previous reports among Costa Ricans [28] and Italians [29]. Contrarily, coffee drinking was significantly lower among Japanese with the $\mathrm{AC}+\mathrm{CC}$ genotype [32]. In a meta-analysis, coffee drinking among Asians was not significantly associated with the rs762551 genotypes [33]. On the other hand, the aforementioned meta-analysis revealed that coffee drinking was significantly higher among Caucasians carrying the rs762551 AA genotype compared to the $\mathrm{AC}+\mathrm{CC}$ genotype [33].

The relationship between coffee and hypertension has been controversial. For instance, a meta-analysis of randomized clinical trials demonstrated a positive

Table 3 Multiple logistic regression model showing the association between coffee drinking and hypertension grouped into the rs762551 genotypes

\begin{tabular}{|c|c|c|c|c|c|c|}
\hline \multirow[t]{2}{*}{ Variables } & \multicolumn{3}{|c|}{ rs762551 AA } & \multicolumn{3}{|c|}{ rs762551 AC $+C C$} \\
\hline & OR & $95 \% \mathrm{Cl}$ & p-value & OR & $95 \% \mathrm{Cl}$ & p-value \\
\hline \multicolumn{7}{|c|}{ Coffee drinking (Reference: No) } \\
\hline Yes & 0.979 & $0.862-1.112$ & 0.7433 & 0.806 & $0.722-0.900$ & 0.0001 \\
\hline \multicolumn{7}{|c|}{ Tea drinking (Reference: No) } \\
\hline Yes & 0.945 & $0.817-1.092$ & 0.4419 & 1.024 & $0.905-1.160$ & 0.7034 \\
\hline \multicolumn{7}{|c|}{ Sex (Reference: Women) } \\
\hline Men & 1.256 & $1.078-1.464$ & 0.0035 & 1.229 & $1.078-1.402$ & 0.0021 \\
\hline Age & 1.096 & $1.088-1.105$ & $<0.0001$ & 1.092 & $1.084-1.099$ & $<0.0001$ \\
\hline \multicolumn{7}{|c|}{ BMI (Reference: Normal) } \\
\hline Underweight & 0.285 & $0.131-0.616$ & 0.0014 & 0.183 & $0.086-0.392$ & $<0.0001$ \\
\hline Overweight & 1.910 & $1.646-2.216$ & $<0.0001$ & 2.100 & $1.847-2.389$ & $<0.0001$ \\
\hline Obesity & 4.290 & $3.659-5.030$ & $<0.0001$ & 4.534 & $3.960-5.190$ & $<0.0001$ \\
\hline \multicolumn{7}{|c|}{ Cigarette smoking (Reference: Never) } \\
\hline Former & 1.200 & $0.980-1.469$ & 0.0779 & 1.133 & $0.951-1.349$ & 0.1612 \\
\hline Current & 0.882 & $0.675-1.153$ & 0.3596 & 1.121 & $0.894-1.407$ & 0.3225 \\
\hline \multicolumn{7}{|c|}{ Alcohol drinking (Reference: Never) } \\
\hline Former & 1.515 & $1.142-2.009$ & 0.0039 & 1.482 & $1.170-1.878$ & 0.0011 \\
\hline Current & 1.471 & $1.154-1.876$ & 0.0018 & 1.283 & $1.040-1.584$ & 0.0199 \\
\hline \multicolumn{7}{|c|}{ Exercise(Reference: No) } \\
\hline Yes & 1.006 & $0.883-1.145$ & 0.9341 & 1.051 & $0.939-1.177$ & 0.3839 \\
\hline
\end{tabular}

Interactions coffee drinking ${ }^{*}$ rs762551 p-value $=0.0303$, tea drinking ${ }^{*}$ rs762551 p-value $=0.4183$. OR: odds ratio, $C l$ : confidence interval 
Table 4 Multiple logistic regression model showing the dose-response association between coffee drinking and hypertension grouped into the rs762551 genotypes

\begin{tabular}{|c|c|c|c|c|c|c|}
\hline \multirow[t]{2}{*}{ Variables } & \multicolumn{3}{|c|}{ rs762551 AA } & \multicolumn{3}{|c|}{ rs762551 AC $+C C$} \\
\hline & OR & $95 \% \mathrm{Cl}$ & p-value & OR & $95 \% \mathrm{Cl}$ & p-value \\
\hline \multicolumn{7}{|c|}{$\begin{array}{l}\text { Coffee drinking } \\
\text { (Reference: no coffee drinking) }\end{array}$} \\
\hline$<1800 \mathrm{ml} /$ week & 1.029 & $0.879-1.205$ & 0.7232 & 0.856 & $0.745-0.983$ & 0.0278 \\
\hline$\geq 1800 \mathrm{ml} /$ week & 0.916 & $0.776-1.081$ & 0.2977 & 0.755 & $0.654-0.872$ & 0.0001 \\
\hline Trend test & & & 0.4037 & & & $<0.0001$ \\
\hline \multicolumn{7}{|c|}{ Tea drinking (Reference: No) } \\
\hline Yes & 0.937 & $0.810-1.084$ & 0.3817 & 1.025 & $0.905-1.161$ & 0.6934 \\
\hline \multicolumn{7}{|c|}{ Sex (Reference: Women) } \\
\hline Men & 1.256 & $1.078-1.465$ & 0.0035 & 1.224 & $1.073-1.396$ & 0.0026 \\
\hline Age & 1.096 & $1.087-1.105$ & $<0.0001$ & 1.091 & $1.084-1.099$ & $<0.0001$ \\
\hline \multicolumn{7}{|c|}{ BMI (Reference: Normal) } \\
\hline Underweight & 0.285 & $0.131-0.616$ & 0.0014 & 0.182 & $0.085-0.390$ & $<0.0001$ \\
\hline Overweight & 1.906 & $1.642-2.212$ & $<0.0001$ & 2.101 & $1.847-2.390$ & $<0.0001$ \\
\hline Obesity & 4.317 & $3.681-5.062$ & $<0.0001$ & 4.537 & $3.963-5.195$ & $<0.0001$ \\
\hline \multicolumn{7}{|c|}{ Cigarette smoking (Reference: Never) } \\
\hline Former & 1.191 & $0.972-1.459$ & 0.0921 & 1.137 & $0.955-1.354$ & 0.1488 \\
\hline Current & 0.880 & $0.672-1.151$ & 0.3512 & 1.126 & $0.897-1.415$ & 0.3059 \\
\hline \multicolumn{7}{|c|}{ Alcohol drinking (Reference: Never) } \\
\hline Former & 1.528 & $1.153-2.027$ & 0.0032 & 1.492 & $1.177-1.891$ & 0.0009 \\
\hline Current & 1.480 & $1.160-1.888$ & 0.0016 & 1.284 & $1.041-1.585$ & 0.0197 \\
\hline \multicolumn{7}{|c|}{ Exercise(Reference: No) } \\
\hline Yes & 1.008 & $0.885-1.148$ & 0.9073 & 1.051 & $0.939-1.177$ & 0.3854 \\
\hline
\end{tabular}

OR: odds ratio, $\mathrm{Cl}$ : confidence interval

but weak association between coffee intake and hypertension [21]. In a follow-up study, coffee intake was associated with higher blood pressure but played a very minute role in the onset of hypertension [34]. In another follow-up study, there was no significant linear association between coffee drinking and hypertension [35]. While a lower risk of hypertension was observed in men who abstained from coffee compared to those who drank moderate amounts, heavy coffee consumption among women was associated with a lower risk of hypertension [36]. In conformity to our observation, results from a Mendelian randomization analysis revealed an inverse association between coffee drinking and hypertension [30]. The seemingly protective effect of coffee against hypertension could in part elucidate why coffee drinking is associated with a lower risk of stroke $[37,38]$. Coffee drinking is also associated with other cardiovascular health benefits, including protection against cerebral infarction [39], coronary heart disease [40], and CVD-related/all-cause mortality [10]. These beneficial effects of coffee are attributed to its richness in polyphenols which possess antihypertensive, antioxidant, and anti-inflammatory properties $[16,41]$.

The observed differences in the relationship between coffee drinking and hypertension are in part due to genetics [42]. Coffee consumption was associated with an increase in CYP1A2 enzyme activity [43]. Moreover, the association of hypertension with coffee drinking was also confirmed to vary according to CYP1A2 genotypes [29]. AA homozygotes compared to AC individuals have greater enzyme activities and are believed to metabolize caffeine relatively fast $[25,44]$. Both moderate and heavy coffee consumption among Italians carrying the $\mathrm{C}$ allele appeared to confer higher susceptibility to hypertension [29]. Swedish individuals with higher caffeine intake carrying the A allele were more likely to have a lower BP and lower risk of hypertension than those carrying the $\mathrm{C}$ allele [30]. In the present study, coffee drinking among Taiwanese adults aged $30-70$ years carrying the AC $+\mathrm{CC}$ genotypes was associated with a lower risk of hypertension. The discrepancy in findings could be due to differences in sample sizes, age, and ethnicity. In the study of Palatino and colleagues (2009), only 553 individuals were 
Table 5 Multiple logistic regression model showing the odds ratios for hypertension according to the combination of coffee drinking and the rs762551 genotypes

\begin{tabular}{|c|c|c|c|}
\hline Variables & OR & $95 \% \mathrm{Cl}$ & $p$ value \\
\hline \multicolumn{4}{|c|}{ Coffee drinking, rs 762551 genotype (Reference: No coffee drinking and AA) } \\
\hline No coffee drinking and $\mathrm{AC}+\mathrm{CC}$ & 1.095 & $0.988-1.215$ & 0.0844 \\
\hline Coffee drinking and $A A$ & 0.975 & $0.859-1.107$ & 0.6960 \\
\hline Coffee drinking and $\mathrm{AC}+\mathrm{CC}$ & 0.888 & $0.789-0.999$ & 0.0483 \\
\hline \multicolumn{4}{|l|}{ Tea drinking (Reference: No) } \\
\hline Yes & 0.989 & $0.900-1.087$ & 0.8222 \\
\hline \multicolumn{4}{|l|}{ Sex (Reference: Women) } \\
\hline Men & 1.239 & $1.122-1.369$ & $<0.0001$ \\
\hline Age & 1.094 & $1.088-1.099$ & $<0.0001$ \\
\hline \multicolumn{4}{|l|}{ BMI (Reference: Normal) } \\
\hline Underweight & 0.222 & $0.129-0.382$ & $<0.0001$ \\
\hline Overweight & 2.017 & $1.830-2.223$ & $<0.0001$ \\
\hline Obesity & 4.430 & $3.997-4.911$ & $<0.0001$ \\
\hline \multicolumn{4}{|l|}{ Cigarette smoking (Reference: Never) } \\
\hline Former & 1.161 & $1.017-1.325$ & 0.0266 \\
\hline Current & 1.013 & $0.852-1.204$ & 0.8850 \\
\hline \multicolumn{4}{|l|}{ Alcohol drinking (Reference: Never) } \\
\hline Former & 1.499 & $1.251-1.797$ & $<0.0001$ \\
\hline Current & 1.364 & $1.164-1.599$ & 0.0001 \\
\hline \multicolumn{4}{|l|}{ Exercise(Reference: No) } \\
\hline Yes & 1.032 & $0.948-1.124$ & 0.4693 \\
\hline
\end{tabular}

OR: odds ratio, Cl: confidence interval

included in the study. Moreover, the age range of the participants was $18-45$ years [29]. We had a relatively large sample size $(n=19,133)$ and the age-range was $30-70$ years. It was proposed that the CYP1A2 enzyme affects BP by differentially inhibiting adenosine receptors (42).

Despite the large sample size, our study is limited in that the TWB questionnaires contained no information on caffeine intake and coffee type. Therefore, we could not determine the interaction between CYP1A2 polymorphism and caffeine or decaffeinated coffee on hypertension risk. Moreover, we defined hypertension based on the Taiwan Biobank questionnaires (as described in the Methods section). This might have resulted in information bias. However, it should be noted that in our initial analyses, we merged the Taiwan Biobank database with the National Health Insurance Research Database (NHIRD) using encrypted personal identification numbers with the resources at the Health and Welfare Data Science Center (HWDC). The NHIRD contained diagnostic codes based on the International Classification of Diseases, Ninth Revision, Clinical Modification (ICD9-CM). Hypertension was identified based on either two outpatient visits or one-time hospitalization between 1998 and 2015 using the diagnostic codes ICD-9-CM
401-405, A260, and A269. Even though we defined hypertension based on self-reports, all cases were those whose diagnosis was confirmed by a medical doctor. Noteworthy, the results observed are similar to those observed when hypertension was defined using ICD codes.

\section{Conclusion}

Generally, coffee drinking was associated with a lower risk of hypertension, while the $\mathrm{AC}+\mathrm{CC}$ genotype was associated with a higher but non-significant risk. Notwithstanding, coffee drinking and rs762551 had a significant interactive relationship. Grouped analyses revealed an inverse association between hypertension and coffee drinking, particularly among individuals with the CYP1A2 rs762551 AC + CC genotype. Our results indicate the possibility of a protective effect of coffee on hypertension and confirm the joint role of coffee and CYP1A2 rs762551 polymorphism on hypertension.

\section{Abbreviations}

BMI: Body mass index; OR: Odds ratio; CVD: Cardiovascular disease; CYP1A2: Cytochrome P450 1A2; SNP: Single nucleotide polymorphism; NHIRD: National Health Insurance Research Database; ICD-9-CM: International Classification of Diseases, Ninth Revision, Clinical Modification; HWDC: Health and Welfare Data Science Center.

\section{Acknowledgements}

Not applicable.

\section{Authors' contributions}

Conceptualization, C-CH, DMT, C-CL, P-HC, H-JY, and Y-PL; Formal analysis, $\mathrm{P}-\mathrm{HC}$ and Y-PL; Methodology, $\mathrm{C}-\mathrm{CH}, \mathrm{DMT}, \mathrm{C}-\mathrm{CL}, \mathrm{P}-\mathrm{HC}, \mathrm{H}-\mathrm{JY}$, and Y-PL; Validation, $\mathrm{C}-\mathrm{CH}, \mathrm{DMT}, \mathrm{C}-\mathrm{CL}, \mathrm{P}-\mathrm{HC}, \mathrm{H}-\mathrm{JY}$, and Y-PL; Writing — original draft, C-CH and DMT; Writing - review \& editing, C-CH, DMT, C-CL, P-HC, H-JY, and Y-PL. All authors read and approved the final manuscript.

\section{Funding}

This work was funded by the University of Foresight Education Project, Ministry of Education, Taiwan-Dementia Health Care Professional Training Program (A-01-108-0-0741) and partly by the Ministry of Science and Technology (MOST), Taiwan (MOST 109-2121-M-040-002, 110-2121-M-040-002110-2121-M-040-002).

\section{Declarations}

Ethics approval and consent to participate

All participants signed an informed consent letter. We obtained ethical approval from the Institutional Review Board of Chung Shan Medical University (CS1-20009).

\section{Consent for publication}

Not applicable.

\author{
Availability of data and materials \\ The data that support the findings of this study are available from Taiwan \\ Biobank but restrictions apply to the availability of these data, which were \\ used under license for the current study, and so are not publicly available. \\ Data are however available from Professor Yung Po Liaw (Email address: \\ Liawyp@csmu.edu.tw, Tel: + 886424730022 ext. 12102; fax: + 886423248179) \\ upon reasonable request and with permission of Taiwan Biobank.
}




\section{Competing interests}

The authors declare that they have no competing interests.

\section{Author details}

'Department of Medical Sociology and Social Work, Chung Shan Medical University, Taichung City, Taiwan. ${ }^{2}$ Department of Social Service, Chung Shan Medical University Hospital, Taichung City, Taiwan. ${ }^{3}$ Department of Medical Imaging, Chung Shan Medical University Hospital, Taichung City, Taiwan. ${ }^{4}$ Department of Public Health and Institute of Public Health, Chung Shan Medical University, No. 110 Sec. 1 Jianguo N. Road, Taichung City 40201, Taiwan. ${ }^{5}$ Department of Physical Medicine and Rehabilitation, Chung Shan Medical University Hospital, Taichung City, Taiwan. ${ }^{6}$ School of Medicine, Chung Shan Medical University, Taichung City, Taiwan. ${ }^{7}$ Department of Family and Community Medicine, Chung Shan Medical University Hospital, Taichung City, Taiwan.

Received: 3 January 2021 Accepted: 30 July 2021

Published online: 14 August 2021

\section{References}

1. Kearney PM, Whelton M, Reynolds K, Muntner P, Whelton PK, He J. Global burden of hypertension: analysis of worldwide data. Lancet. 2005;365(9455):217-23.

2. Mills KT, Bundy JD, Kelly TN, Reed JE, Kearney PM, Reynolds K, et al. Global disparities of hypertension prevalence and control: a systematic analysis of population-based studies from 90 countries. Circulation. 2016;134(6):441-50.

3. Chiang C-E, Wang T-D, Ueng K-C, Lin T-H, Yeh H-I, Chen C-Y, et al. 2015 Guidelines of the Taiwan Society of Cardiology and the Taiwan Hypertension Society for the Management of Hypertension. J Chin Med Assoc. 2015;78(1):1-47.

4. Geleijnse JM. Habitual coffee consumption and blood pressure: an epidemiological perspective. Vascular Health Risk Manag. 2008;4(5):963.

5. Stamler J, Stamler R, Neaton JD. Blood pressure, systolic and diastolic, and cardiovascular risks: US population data. Arch Intern Med. 1993;153(5):598-615.

6. Lawes CM, Vander Hoorn S, Rodgers A. Global burden of blood-pressurerelated disease, 2001. Lancet. 2008;371(9623):1513-8.

7. Roth GA, Huffman MD, Moran AE, Feigin V, Mensah GA, Naghavi M, et al. Global and regional patterns in cardiovascular mortality from 1990 to 2013. Circulation. 2015;132(17):1667-78.

8. Roth GA, Johnson C, Abajobir A, Abd-Allah F, Abera SF, Abyu G, et al. Global, regional, and national burden of cardiovascular diseases for 10 causes, 1990 to 2015. J Am Coll Cardiol. 2017;70(1):1-25.

9. De Caterina R, El-Sohemy A. Moving towards specific nutrigenetic recommendation algorithms: caffeine, genetic variation and cardiovascular risk. Lifestyle Genomics. 2016;9(2-4):106-15.

10. Loftfield E, Cornelis MC, Caporaso N, Yu K, Sinha R, Freedman N. Association of coffee drinking with mortality by genetic variation in caffeine metabolism: findings from the UK Biobank. JAMA Intern Med. 2018;178(8):1086-97.

11. Wann J-W, Kao C-Y, Yang Y-C. Consumer preferences of locally grown specialty crop: The Case of Taiwan Coffee. Sustainability. 2018;10(7):2396.

12. Slama M, Susic D, Frohlich ED. Prevention of hypertension. Curr Opin Cardiol. 2002;17(5):531-6.

13. D'Elia L, La Fata E, Galletti F, Scalfi L, Strazzullo P. Coffee consumption and risk of hypertension: a dose-response meta-analysis of prospective studies. Eur J Nutr. 2019;58(1):271-80.

14. Navarro AM, Martinez-Gonzalez MA, Gea A, Ramallal R, Ruiz-Canela $M$, Toledo $E$. Coffee consumption and risk of hypertension in the SUN Project. Clin Nutr. 2019;38(1):389-97.

15. Grosso G, Micek A, Godos J, Pajak A, Sciacca S, Bes-Rastrollo M, et al. Long-term coffee consumption is associated with decreased incidence of new-onset hypertension: a dose-response meta-analysis. Nutrients. 2017;9(8):890

16. Larsson SC. Coffee, tea, and cocoa and risk of stroke. Stroke. 2014;45(1):309-14.

17. Mahdavi-Roshan M, Salari A, Ghorbani Z, Ashouri A. The effects of regular consumption of green or black tea beverage on blood pressure in those with elevated blood pressure or hypertension: a systematic review and meta-analysis. Complement Therap Med. 2020;51:102430.

18. Steffen M, Kuhle C, Hensrud D, Erwin PJ, Murad MH. The effect of coffee consumption on blood pressure and the development of hypertension: a systematic review and meta-analysis. J Hypertens. 2012;30(12):2245-54.

19. Miranda AM, Goulart AC, Benseñor IM, Lotufo PA, Marchioni DM. Coffee consumption and risk of hypertension: a prospective analysis in the cohort study. Clin Nutr. 2020;40:542.

20. Hamer M. Coffee and health: explaining conflicting results in hypertension. J Hum Hypertens. 2006;20(12):909-12.

21. Noordzij M, Uiterwaal CS, Arends LR, Kok FJ, Grobbee DE, Geleijnse JM. Blood pressure response to chronic intake of coffee and caffeine: a metaanalysis of randomized controlled trials. LWW. 2005;23:921.

22. Grosso G, Stepaniak U, Polak M, Micek A, Topor-Madry R, Stefler D, et al. Coffee consumption and risk of hypertension in the Polish arm of the HAPIEE cohort study. Eur J Clin Nutr. 2016;70(1):109-15.

23. Zhang Z, Hu G, Caballero B, Appel L, Chen L. Habitual coffee consumption and risk of hypertension: a systematic review and meta-analysis of prospective observational studies. Am J Clin Nutr. 2011;93(6):1212-9.

24. Yang A, Palmer AA, de Wit H. Genetics of caffeine consumption and responses to caffeine. Psychopharmacology. 2010;211(3):245-57.

25. Sachse C, Brockmöller J, Bauer S, Roots I. Functional significance of a C $\rightarrow$ A polymorphism in intron 1 of the cytochrome P450 CYP1A2 gene tested with caffeine. Br J Clin Pharmacol. 1999:47(4):445-9.

26. Mao Y, Yang L, Chen Q, Li G, Sun Y, Wu J, et al. The influence of CYP1A1 and CYP1A2 polymorphisms on stroke risk in the Chinese population. Lipids Health Dis. 2020;19(1):1-9.

27. Rasmussen BB, Brix TH, Kyvik KO, Brøsen K. The interindividual differences in the 3-demthylation of caffeine alias CYP1A2 is determined by both genetic and environmental factors. Pharmacogenet Genomics. 2002:12(6):473-8.

28. Cornelis MC, El-Sohemy A, Kabagambe EK, Campos H. Coffee, CYP1A2 genotype, and risk of myocardial infarction. JAMA. 2006;295(10):1135-41.

29. Palatini P, Ceolotto G, Ragazzo F, Dorigatti F, Saladini F, Papparella I, et al. CYP1A2 genotype modifies the association between coffee intake and the risk of hypertension. J Hypertens. 2009;27(8):1594-601.

30. Guessous I, Dobrinas M, Kutalik Z, Pruijm M, Ehret G, Maillard M, et al. Caffeine intake and CYP1A2 variants associated with high caffeine intake protect non-smokers from hypertension. Hum Mol Genet. 2012;21(14):3283-92.

31. Soares RN, Schneider A, Valle SC, Schenkel PC. The influence of CYP1A2 genotype in the blood pressure response to caffeine ingestion is affected by physical activity status and caffeine consumption level. Vascul Pharmacol. 2018;106:67-73.

32. Kohno M, Tajima O, Uezono K, Tabata S, Abe H, Adachi M, et al. Cytochrome P450 1A2 polymorphisms, coffee consumption and impaired glucose metabolism in Japanese men. Endocrinol Metab Syndr. 2013;2:119.

33. Denden S, Bouden B, Haj Khelil A, Ben Chibani J, Hamdaoui M. Gender and ethnicity modify the association between the CYP1A2 rs762551 polymorphism and habitual coffee intake: evidence from a meta-analysis. Genet Mol Res. 2016;15(2).

34. Klag MJ, Wang N-Y, Meoni LA, Brancati FL, Cooper LA, Liang K-Y, et al. Coffee intake and risk of hypertension: the Johns Hopkins precursors study. Arch Intern Med. 2002;162(6):657-62.

35. Winkelmayer WC, Stampfer MJ, Willett WC, Curhan GC. Habitual caffeine intake and the risk of hypertension in women. JAMA. 2005;294(18):2330-5

36. Uiterwaal CS, Verschuren WM, Bueno-de-Mesquita HB, Ocké M, Geleijnse $\mathrm{JM}$, Boshuizen $\mathrm{HC}$, et al. Coffee intake and incidence of hypertension. Am J Clin Nutr. 2007;85(3):718-23.

37. Lopez-Garcia E, Rodriguez-Artalejo F, Rexrode KM, Logroscino G, Hu FB, van Dam RM. Coffee consumption and risk of stroke in women. Circulation. 2009:119(8):1116.

38. Larsson SC, Virtamo J, Wolk A. Coffee consumption and risk of stroke in women. Stroke. 2011:42(4):908-12.

39. Larsson SC, Männistö S, Virtanen MJ, Kontto J, Albanes D, Virtamo J. Coffee and tea consumption and risk of stroke subtypes in male smokers. Stroke. 2008;39(6):1681-7.

40. Liu Y-T, Tantoh DM, Wang L, Nfor ON, Hsu S-Y, Ho C-C, et al. Interaction between coffee drinking and TRIB1 rs17321515 single nucleotide 
polymorphism on coronary heart disease in a Taiwanese population. Nutrients. 2020;12(5):1301.

41. Butt MS, Sultan MT. Coffee and its consumption: benefits and risks. Crit Rev Food Sci Nutr. 2011;51(4):363-73.

42. Guessous I, Eap CB, Bochud M. Blood pressure in relation to coffee and caffeine consumption. Curr Hypertens Rep. 2014;16(9):468.

43. Djordjevic N, Ghotbi R, Bertilsson L, Jankovic S, Aklillu E. Induction of CYP1A2 by heavy coffee consumption in Serbs and Swedes. Eur I Clin Pharmacol. 2008;64(4):381-5.
44. Castorena-Torres F, Mendoza-Cantú A, De León MB, Cisneros B, ZapataPérez O, López-Carrillo L, et al. CYP1A2 phenotype and genotype in a population from the Carboniferous Region of Coahuila. Mexico Toxicol Lett. 2005;156(3):331-9.

\section{Publisher's Note}

Springer Nature remains neutral with regard to jurisdictional claims in published maps and institutional affiliations.
Ready to submit your research? Choose BMC and benefit from:

- fast, convenient online submission

- thorough peer review by experienced researchers in your field

- rapid publication on acceptance

- support for research data, including large and complex data types

- gold Open Access which fosters wider collaboration and increased citations

- maximum visibility for your research: over $100 \mathrm{M}$ website views per year

At BMC, research is always in progress.

Learn more biomedcentral.com/submissions 